\title{
Extraction of the inherent nature of wind speed using wavelets and FFT
}

\author{
Md. Mahbub Alam ${ }^{a^{*}}$, S. Rehman ${ }^{\text {b }}$, L. M. Al-Hadhrami ${ }^{\text {b }}$, J.P. Meyer ${ }^{\mathrm{c}}$ \\ ${ }^{\mathrm{a}}$ Harbin Institute of Technology, Shenzhen Graduate School, Shenzhen, China \\ ${ }^{\mathrm{b}}$ Center for Engineering Research, Research Institute, King Fahd University of Petroleum and Minerals, Dhahran- \\ 31261, Saudi Arabia and \\ ${ }^{\mathrm{c}}$ Mechanical and Aeronautical Engineering Department, University of Pretoria, Pretoria, South Africa
}

\begin{abstract}
Due to the availability of multi-megawatt wind turbines, ease of installation and maintenance, economic compatibility and commercial acceptance, the power of the wind is being used globally for both grid-connected and off-grid applications. The power of the wind is intermittently available due to the fluctuating nature of the wind and hence needs to be understood well. Therefore, its variability in time and spatial domain was studied. The present work utilized daily mean values of wind speed from different meteorological stations spread over the Kingdom of Saudi Arabia in conjunction with wavelet transform and fast Fourier transform power spectrum techniques to understand the dynamic nature of the wind at nine stations. The study found that wind speed changed by \pm 0.6 to \pm 1.6 knots over a long period of about 10 years depending on the locations. The long-term mean wind speed of 5.6, 8.9, 6.25, 8.1, 6.0, 7.1, 6.0, 8.6 and 7.3 knots were obtained at Abha, Dhahran, Gizan, Guriat, Hail, Jeddah, Riyadh, Turaif and Yanbu, respectively.
\end{abstract}

Keywords: Wind energy, wind speed, wavelet, fast Fourier transform, power spectrum

\section{Introduction}

When thinking of installing a wind firm at a site, an indispensable task is to conduct an onsite wind speed measurement campaign for a few years (the longer the better) and analyze the measured data to extract information on the variability of the wind (Jaramillo and Borja 2004). The variability covers a wide spectrum of time-scales from seconds to several years, say, random variation at very short interval (turbulence scale), synoptic scale, seasonal variation, annual cycle variation etc. This statistical information is required not only for a feasibility study of the wind firm to be installed but also for wind power prediction at different years/seasons/months/day as 
well as wind turbine control. This article provides statistical information about wind speed nature for a long time in the past which is direly needed for long-term wind speed predictions. Furthermore, without analytical prediction, the statistical information on variations of past wind at different at time-scales can give us a rough idea about how the wind will behave in the near future (Garcia-Marin et al. 2013).

The alarmingly increasing adverse effects of global warming and climate change have been dictating an immediate cut in fossil fuel burning and at the same time, an exponential increase in clean energy development and utilization. At present, the power of the wind has become a commercially available and financially acceptable technology of the modern era. Hence for proper and optimal utilization of wind power, understanding of its characteristics in time and spatial domains has become essential. Short- and long-range wind forecasts over different time periods are becoming important requirements for the management of wind farms. Time series modeling of wind speeds is based on the valid assumption that all the causative factors are implicitly accounted for in the sequence of occurrence of the process itself. Wind speed characteristics have been reported worldwide using statistical, mathematical, empirical and physical time series analysis (Fourier transform, wavelet transform, detrended fluctuation analysis, artificial neural networks, Hurst exponent, autoregressive moving averages, etc.). In recent times, power spectral density and wavelet transforms have been employed as useful tools to analyze measured wind speed data in particular and meteorological data in general.

Usually, most of the signals contain numerous non-stationary or transitory characteristics such as drift, trends, abrupt changes, and beginnings and ends of events. These characteristics are often the most important part of the signal and are needed to be analyzed to understand physical phenomena hidden behind the signal. To study these characteristics, wavelets have been being developed since the early eighties. Wavelet analysis methods allow the use of long time intervals where we want more precise low-frequency information, and shorter regions where we want high-frequency information. One major advantage afforded by wavelets is the ability to perform local analysis, that is, to analyze a localized area of a larger signal.

Kitagawa and Nomura (2003) used the inverse wavelet transform method to generate wind velocity fluctuations. To investigate the timescale structure of natural wind, the wavelet transform was applied to the time history of measured wind velocity data. Yamada and Ohkitani (1991) applied the wavelet transform on historical time series of wind data and estimated the 
probability density functions (PDFs) of the wavelet coefficients. Their results showed that PDFs of the wavelet coefficients for small-scale fluctuations deviated from the Gaussian distribution, though the power spectrum agreed with Kolmogorov's $-5 / 3$ law. The inverse Fourier transform is a traditional method to generate time histories (Shinozuka and Deodatis 1991) but it fails to reflect time-dependent characteristics of the data. Pettit et al. (2002) applied the wavelet transform to the time data of roof-corner pressures with extreme local loads and obtained the PDFs on the time-dependent characteristics of the pressure transients. Based on these PDFs, a method to generate synthetic signals was developed, and time histories similar to the original roof-corner pressure data were composed. Aksoy et al. (2004) introduced a new wind speed data generation scheme based on wavelet transformation and compared this scheme with existing wind speed generation methods. Their results proved that the proposed wavelet-based method was found to be the best for wind speed data generation compared with existing methods.

Turbelin et al. (2009) estimated wavelet cross-coherence, wavelet cross-correlation and spectral wavelet cross-correlation coefficients and displayed these as functions of the equivalent Fourier period. The study found that the ANN models were effective in computing the largescale fluctuations of large amplitude. Chellali et al. (2010) applied wavelet transform as a timefrequency analysis to meteorological data for the region of Adrar, Algeria. They conducted this analysis to investigate the power spectra behaviors of wind speed and its variations with time. The results showed significant synoptic oscillations for periods of 2 to 16 days in the cold weather. The wavelet power spectrum also revealed the presence of intra-seasonal oscillations for periods of 30 to 60 days. Giorgi (2011) proposed a wind speed prediction system based on the wavelet decomposition technique and forecasted the wind speed in two time horizons ( 1 and $24 \mathrm{~h}$ ) with acceptable accuracy compared with other techniques. Chellali et al. (2011) reported a stochastic and cyclic study of wind speed behavior at Hassi-R'mel meterological data collection site in Adrar, Algeria by fitting the wind speed data to Weibull distribution and the usage of time-frequency analysis. The results showed that the spectrum wind process was able to enfold many limited interval oscillations which is not possible with other methods. During the last decade, wavelets have been extensively employed as a tool to analyze measured data in general and wind data in particular to study the wind effects on structures (Rossi 2004), feature extraction for wind turbine vibration signals (Tang et al. 2010; Liu et al. 2010; Jiang et al. 2011; 
Karegar and Sobhani 2012) and to evaluate the quality of synthetic wind speed signals (Karem and Kijewski 2002).

The inverse wavelet transform is also used to generate a time series of historical data (Gurley et al. 1997). Applying the log-Poisson turbulence model, Dubrulle (1994) and She and Waymire (1995) generated wavelet coefficients and time histories of turbulence. Hang et al. (2010) used wavelet transform (WT) with fixed and adaptive machine learning/time series models (multilayer perceptron (MLP), radial basis functions, linear regression, or GARCH) for short-term electricity demand and gas price forecasting. The results showed that the prediction accuracy was improved by using the WT and adaptive models. With reference to Saudi Arabia, Abdel-Aal and Al-Garni (1997) used univariate time series analysis for the prediction of electric energy consumption for the eastern region of the country. Politis et el. (2012) used computational fluid dynamics to predict wind power production from wind farms in complex terrain and to study the wake flow patterns. Catalão et al. (2011) used artificial neural networks in combination with wavelet transform for short-term wind power forecasting. Costa et al. (2000) made a brief review of the last 30 years of the history of wind power short-term prediction, from the first ideas and sketches on the theme to the actual state of the art on models and tools, with the emphasis on the most significant proposals and developments. Several studies have been conducted in different regions of the globe for different time scales and frequency ranges using wavelet transform, artificial neural networks and the cross-wavelet transform such as the study of turbulence (Costa et al. 2008; Farge 1992), tropical convection (Weng and Lau 1994), electricity demand forecast (Ekonomou 2010), intra-decadal changes in the ENSO monsoon system (Torrence and Compo 1998), intra-seasonal oscillations in wind speed and oceanic wave (Lee at al 2007), relationships between solar activities and some large-scale climatic parameters (Velasco and Mendoza 2008) and wind turbine vibration signal analysis (Xueli et al. 2011).

When the wind has salient periodic features only over limited intervals of times, a global Fourier analysis is theoretically possible; but it may not be practical or efficient. The Fourier transform is limited because an analysis with single window cannot detect features in the signal that are either much longer or much shorter than the window size. Therefore, to have better representation of the wind spectrum for such case, we should seek a representation that is capable of following the wind spectrum as it varies with time. Such representation is known by Time-Frequency Representation (TFR). Autocorrelation involves matching the signal with a 
copy of that signal, which is extended or delayed in the time axis, identifying the presence of a periodic signal removing noise. But it cannot decompose a signal at different frequencies. On the other hand, the wavelet analysis decomposes a signal into sub-signals at different frequency bands, where the amplitude of the signal at each frequency band is clearly visible. When the decomposition is done in a dyadic (orthogonal) scale adopted presently, it is possible to reconstruct the original signal using either deconvolution or inverse filter, without redundancy (Yang 1998 ). The signals of meteorological parameters of the Kingdom of Saudi Arabia have so much noise that their overall shape is not apparent upon visual inspection but trends become clearer with each approximation. Thus, wavelet analysis is useful in revealing signal trends, a goal that is complementary to the one of revealing a signal hidden in the noise. If the signal itself includes sharp changes, then successive approximations look less and less similar to the original signal. A repeating pattern in the wavelet coefficient plots is characteristic of a signal that looks similar on many scales. If a signal is similar to itself at different scales, then the wavelet coefficients will also be similar at different scales. In the coefficients plot, which shows scale on the vertical axis, this self-similarity generates a characteristic pattern.

The main objective of the present work is to understand the fluctuating nature of the wind using wavelet and fast Fourier transform power spectrum techniques which are very useful to quantify the highly fluctuating natural phenomenon. Wind power industry is competing with the conventional power systems and hence accurate prediction of wind speed in future time domain is very helpful in assuring quality energy supply. Furthermore, the wind and other meteorological measurements are sparsely available and hence these methods can also be used to estimate values at locations where measurements are not available.

\section{Mathematical description of wavelet methodology}

In plots, the $x$-axis represents a position along the signal (time), the $y$-axis represents scale, and the color at each point represents the magnitude of the coefficient. An inspection of the continuous wavelet coefficient plot reveals patterns among scales and shows the signals' possibly fractal nature. Calculating the wavelet coefficient at every possible scale is a fair amount of work, and it generates an awful lot of data. It turns out that if we choose scales and positions based on powers of two, so-called dynamic scales and positions, and then analysis 
becomes much more efficient and accurate. The low-frequency content is the most important part. The high-frequency content, on the other hand, imparts flavor or nuance. Any signal (function) can be decomposed into two parts called approximation and details. The approximations are the high-scale, low-frequency components of the signal. The details are the low-scale, high frequency components. In this section, we apply MATLAB TOOL-BOX to detect discontinuities, long-term evolution and self-similarity of the signals of meteorological parameters of nine meteorological stations of the Kingdom of Saudi Arabia. Mellit et al. (2006) used adaptive wavelet-network model for forecasting daily total solar radiation data.

The first- and second-level details show the discontinuity most clearly, because the rupture contains the high-frequency part. The presence of noise, which is fairly common in signal processing, makes identification of discontinuities more complete. If the first levels of the decomposition can be used to eliminate a large part of the noise, the rupture is sometimes visible at deeper levels in the decomposition. In order to detect a singularity, the selected wavelet must be sufficiently regular, which implies a longer filter impulse response.

The name wavelet means small wave, and in brief, a wavelet is an oscillation that decays quickly. The equivalent mathematical conditions are as follows:

$\int_{-\infty}^{\infty}|\psi(t)|^{2} d t<\infty$

$\int_{-\infty}^{\infty} \psi(t) d t=0$

Admissibility condition

$\int_{-\infty}^{\infty} \frac{|\psi(\xi)|^{2}}{|\xi|} d \xi<\infty$

In wavelet theory, a function is represented by the infinite series expansion in terms of the dilated and translated version of a basis function and called the mother wavelet satisfying the above conditions:

$\psi_{a, b}(t)=a^{-\frac{1}{2}} \psi\left(\frac{t-b}{a}\right)$, where $a>0$ 
$T_{\psi} f(a, b)=a^{-1 / 2} \int_{-\infty}^{\infty} f(t) \psi\left(\frac{t-b}{a}\right) d t=<\left(f, \psi_{a, b}\right)>=$ inner product of $f$ and $\psi_{a, b}$

where $T_{\psi} f(a, b)$ is called the wavelet transform of function $f(t)$. A wavelet transform $T_{\psi}$ decomposes a signal into several groups of coefficients. Different coefficient vectors contain information about the characteristics of the sequence at different scales. It may be observed that the wavelet transform is a prism, which exhibits properties of a signal such as points of abrupt changes, seasonality or periodicity. The wavelet transform is a function of the scale of frequency (a) and is the spatial position or time (b). The plane defined by the variables (a, b) is called the scale-space or time-frequency plane. The wavelet transform $T_{\psi} f(a, b)$ measures the variation of $f$ in the neighborhood of $b$. For a compactly supported wavelet (for a wavelet vanishing outside a closed and bounded interval), the value of $T_{\psi} f$ depends on the value of $f$ in the neighborhood of $b$ of size proportional to the scale $a$. At small scales, $T_{\psi} f(a, b)$ provides localized information such as localized regularity (smoothness) of $f$. The global and local Lipschitz regularity can be characterized by the asymptomatic decay of wavelet transformation at small scales.

\section{Sites and data description}

The Kingdom of Saudi Arabia lies between latitudes $31^{\circ} \mathrm{N}$ and $17.5^{\circ} \mathrm{N}$ and longitudes $50^{\circ} \mathrm{E}$ and $36.6^{\circ}$ E. The land elevation varies between $0 \mathrm{~m}$ to $2,600 \mathrm{~m}$ above the mean sea level. Complex terrain is found in the southwest region of the Kingdom. The east and the west coasts of the Kingdom are located on the Arabian Gulf and Red Sea, respectively. Mainly two seasons, winter and summer, are observed during the year. The historical meteorological data collected at national and international airports in the Kingdom show a long term annual wind speed of about 7 to 9 knots at different locations at about 10 meters above ground level (AGL).

The latitude, longitude, altitude, and data collection period for national and international airports are summarized in Table 1 and the physical locations are depicted in Figure 1. In general, the data collection period varied from 1970 to 2006 for most of the data collection stations. At all of these stations, the hourly values of all the parameters such as wind speed (WS), wind direction (WD), dry bulb temperature $(T)$, wet bulb temperature $\left(\mathrm{T}_{\mathrm{w}}\right)$, station pressure $(\mathrm{P})$, 
sea level pressure $\left(\mathrm{P}_{\mathrm{sl}}\right)$, relative humidity $(\mathrm{RH})$, vapor pressure $\left(\mathrm{V}_{\mathrm{p}}\right)$, total rainfall $(\mathrm{R})$, and others are recorded manually and then daily average, maximum and minimum values are saved on the computer. The meteorological stations at Yanbu, Jeddah, Gizan, and Dhahran are situated near the coast. Hence these stations could be considered as representatives of coastal locations. Table 2 provides the details (type of sensors, sensitivity, threshold, etc.) about different meteorological sensors installed at these sites. The actual wind measurements were made in knots $(1 \mathrm{knot}=$ $0.515 \mathrm{~m} / \mathrm{s}$ ), so to avoid truncation errors without any added advantage, the units of wind speed has been preferred in "knots" presently.

\section{Table 1}

Site specific information of meteorological stations considered in this study

\begin{tabular}{lcccccc}
\hline Location & From & To & $\begin{array}{c}\text { Latitude } \\
\left({ }^{\circ} \mathrm{N}\right)\end{array}$ & $\begin{array}{c}\text { Longitude } \\
\left({ }^{\circ} \mathrm{E}\right)\end{array}$ & $\begin{array}{c}\text { Altitude } \\
(\mathrm{m})\end{array}$ & $\begin{array}{c}\text { Anemometer } \\
\text { Height }(\mathrm{m})^{*}\end{array}$ \\
\hline Abha & $01 / 09 / 1983$ & $31 / 12 / 2006$ & 18.20 & 42.70 & 2084 & 10 \\
Dhahran & $01 / 01 / 1970$ & $31 / 12 / 2006$ & 26.30 & 50.20 & 17 & 10 \\
Gizan & $01 / 01 / 1970$ & $31 / 12 / 2006$ & 16.90 & 42.60 & 3 & 8 \\
Guriat & $01 / 01 / 1984$ & $31 / 12 / 2006$ & 31.40 & 37.30 & 499 & 12 \\
Hail & $01 / 01 / 1990$ & $30 / 11 / 2006$ & 27.40 & 41.70 & 1013 & 9 \\
Jeddah & $01 / 01 / 1970$ & $31 / 12 / 2006$ & 21.70 & 39.20 & 12 & 10 \\
Riyadh & $01 / 04 / 1984$ & $31 / 12 / 2006$ & 24.70 & 46.70 & 612 & 10 \\
Turaif & $03 / 08 / 1970$ & $31 / 12 / 2006$ & 31.70 & 38.70 & 813 & 10 \\
Yanbu & $22 / 02 / 1977$ & $31 / 12 / 2006$ & 24.20 & 38.10 & 14 & 10 \\
\hline \multicolumn{7}{c}{ *Above ground level }
\end{tabular}

Table 2

Operating ranges and accuracies of various sensors used for data collection.

\begin{tabular}{cccccc}
\hline Sensor type & Technical & Accuracy & Range & Threshold & Output \\
\hline Wind speed & AC sine wave & $0.1 \mathrm{~m} / \mathrm{s}$ & $1-96 \mathrm{~m} / \mathrm{s}$ & $0.78 \mathrm{~m} / \mathrm{s}$ & $0-125 \mathrm{HZ}$ \\
Wind direction & Mechanical & $1 \%$ & $0-360^{\circ}$ & $1 \mathrm{~m} / \mathrm{s}$ & 0 -Exc. \\
Temperature & - & $\pm 1.1^{\circ} \mathrm{C}$ & $-40^{\circ} \mathrm{C}$ to $52.5^{\circ} \mathrm{C}$ & - & $0-2.5$ volts DC \\
Barometric pressure & - & $\pm 15 \mathrm{mb}$ & $150-1150 \mathrm{mb}$ & & Linear voltage \\
\hline
\end{tabular}

\section{Results and Discussion}

Wind speed is a highly random meteorological phenomenon and changes with the time of the day, month, year, etc., and with geographical location. It is very difficult to predict the trend of wind speed both in time and spatial domains. In order to evaluate the frequency content of the time series of wind speed data, fast Fourier transforms (FFTs) providing power spectral density 
(PSD) are widely used. FFTs are useful to extract frequencies in a stationary or transient signal as well as their predominance over the entire time series. These are discussed in details in the forthcoming sub-section.

\section{Spectral signature of wind speeds characteristics (using FFT)}

In this section, illuminations are shed on FFT analysis results of wind speed time series data recorded at nine different locations, namely Abha, Dhahran, Gizan, Guriat, Hail, Jeddah, Riyadh, Turaif and Yanbu in Saudi Arabi. Wind speed data are obtained from the nine weather stations in Saudi Arabia, showing great potential for application in verifying the current criteria used for design practices. The FFT analysis is done through MATLAB software, which provides a very useful function in FFT algorithm. Parameters of engineering significance such as hidden periodicities, frequency components, absolute magnitude and phase of the transformed data, power spectral density and cross-spectral density can be obtained. Here data analysis of daily average wind speed time series data is done for 1990 to 2005 . The data was scanned every three seconds and 10-minute average values were recorded. Finally, the daily average values were obtained using 144 10-minute average values recorded during 24 hours. The total number of daily average data points in the time series for 1990 to 2005 is 5960.

The power spectra of daily average wind speed time series data at the nine locations are shown in Figure 2. While the horizontal axis represents the frequency $(f)$, the vertical axis shows energy at the frequency. Abha is a station with many hills around. As seen in Figure 2(a) for Abha, power spectral energy mostly concentrates on a low frequency range $0.002-0.006$ with a peak at $f=0.0027$. The peak corresponds to a period of about $T=1 / f \approx 370$ days $\approx$ one year, implying that wind speed variation in a year is similar to that in another at least qualitatively. One should not be confused with the 370 days; the least deviation from exactly 365 days arises from the frequency resolution in the FFT analysis. The $f=0.006$ over which energy decays corresponds to about half a year. That is the half-year repetition in wind speed also exists. Dhahran is a coastal site $3 \mathrm{~km}$ inland from the Arabian Gulf. There is a small single-storey airport building in the vicinity of the meteorological station. The station is $17 \mathrm{~m}$ above the mean sea level and the wind direction is mostly from the sea to the station. Here the peak corresponding to annual repetition $(f=0.0027)$ is more clear (Figure $2 \mathrm{~b}$ ). However, the half-year recurrence that appeared at Abha is not explicit. The high-frequency energies $(f>0.02)$ at 
Dhahran (Figure 2b) are larger than those at Abha (Figure 2a). A small peak emerges at $f=$ 0.074 at Dahran, which communicates to biweekly repetition of wind speed. The biweekly change in wind speed may be a unique feature for a coastal area as it is observed in other coastal area, namely Yanbu, which will be presented later.

Gizan is a coastal station on the west coast of Saudi Arabia, some 100 meters inland. There are one small single-storey airport building and some trees around. This station is only $5 \mathrm{~m}$ above the mean sea level. The Red Sea is a bit more turbulent than the Arabian Gulf on the east coast (Dhahran) and is wide open. Therefore, the annual and biweekly peaks are not as dominant as those in Abha or Dhahran (Figure 2c). Another cause may be that the site is only $5 \mathrm{~m}$ above the sea level. Guriat is an inland station with high land and small hills with gentle topographical features. Since the station is high, the annual recurrence $(f=0.0027)$ is more dominant than that at Abha and Dhahran (Figure 2d). Hail is a highland plateau in the north central area of Saudi Arabia. As seen in Figure 2(e), speed varies not only annually $(f=0.0027)$ but also at further low frequencies $(f<0.0027)$, e.g. two- and three-year repetitions which will be further clarified through wavelet analysis results later.

Jeddah station is around $10 \mathrm{~km}$ inland from the Red Sea. The FFT power spectrum for this station is presented in Figure 2(f). There are many buildings around and it is situated in an urban area. The wind blows from the sea inwards and is intercepted by high-rise buildings and structures such as bridges and other industrial installations. Due to this confrontation of wind with structures, the annual maximum wind speed is smaller compared with that in Abha, Dahran, Guriat and Hail. Gizan also has similar power spectra because of wind obstructed by trees. The presence of high-rise buildings and/or trees makes the flow boundary layer wider, resulting in a smaller speed. The FFT power spectrum obtained using long-term mean wind speed data for Riyadh is shown in Figure 2(g). Riyadh station is on the mainland and is around $450 \mathrm{~m}$ above the mean sea level. Riyadh is the capital of Saudi Arabia, hence it is a very developed region and surrounded by high-rise buildings, bridges and various industrial installations. The winds are prevalent from the northern and north-western direction in this region. Since the site is quite high above sea level, the annual variation is evident.

The FFT power spectrum for Turaif is shown in Figure 2(h). Turaif is a small city in the northernmost part of Saudi Arabia and is a hilly inland area. The wind blows mostly from the north onto this area and accelerates due to topographical features. The power spectrum displays 
low-frequencies variation $(f<0.0027)$, having similar characteristics to that at Hail. Yanbu is a coastal site on the Red Sea in the north-west of Saudi Arabia. It is an industrial area and is surrounded by a range of hills on the northern side and exposed to the sea on its western side. The station is $10 \mathrm{~m}$ above the mean sea level. The peak at $f=0.0027$ is sharp, indicating the annual variation in wind speed is very regular (see Figure 2(i)). A biweekly variation also exists. A scrupulous observation of all the FFT figures reveals that Abha, Dhahran, Guriat and Yanbu having a sharp peak at $f=0.0027$ retain a more regular annual repetition of wind speed than Gizan, Hail, Jeddah, Riyad and Turaif. Wavelet analysis results will provide more details.

\section{Intrinsic features of wind speed (using wavelet decomposition)}

While the Fourier transform produces averaged spectral coefficients, which are independent of time and are useful to identify the dominant frequencies in a signal, the wavelet transform provides a potentially more revealing picture of the time-frequency localization of signals including signal decomposition at various frequencies. For a long-term wind speed signal, a decomposition of signal at various frequencies is very valuable to the understanding of the inherent characteristics of wind (Costa et al. 2008; Alam et al. 2003, 2005).

A discrete wavelet analysis of the daily mean values of wind speed time series data was conducted over a period of 1990 - 2005 at the nine locations (Abha, Dhahran, Gizan, Guriat, Hail, Jeddah, Riyadh, Turaif and Yanbu) using db8. Naturally the daily mean signal captures information for a period of longer than 2 days following the Nyquist frequency criterion. The decomposition analysis results of wind speed data for Abha, Dhahran, Gizan, Guriat, Hail, Jeddah, Riyadh, Turaif and Yanbu are shown in Figs. 3 to 11, respectively. In these figures the $x$ axis presents the number of days $(D)$ of the entire data period (1990 to 2005) used in this study. Each of these figures has 10 parts. The first part ' $\mathrm{S}$ ' represents the signal or raw data and the second part ' $\mathrm{a}_{8}$ ' corresponds to the amplitude of the signal for wavelet Daubechies $(\mathrm{db})$ at level 8 corresponding to a period of longer than 512 days. Note that that the dashed line in as signal is not an output of the analysis, but just a hand sketch showing the low-frequency trend. The last

eight parts, i.e. $d_{1}, d_{2}, d_{3}, d_{4}, d_{5}, d_{6}, d_{7}$ and $d_{8}$ of these figures represent details of decomposed signals of the raw data at eight different levels corresponding to a period range of 2 to 4,4 to 8,8 to 16,16 to 32,32 to 64,64 to 128,128 to 256 and 256 to 512 days, respectively. 
The raw signal ' $\mathrm{S}$ ' in Figure 3 (Abha) displays a sharp spike at $D=1200$ and a nearly regular variation of speed. The nearly regular variation is evident in the $d_{8}$ signal with a periodicity of approximately 365 days (one year), forming a peak between June and August of each year. The minimum speed occurs sometime in December to January. The fluctuation of the speed is relatively high, -2.5 to 2.5 knots for $D<3300(<1998)$ and -2 to 2 knots for $D>5000(>2003)$ and small, -1 to 1 knots for $D=3300$ to 5000 corresponding to year 1998 to 2003 . On an average, the fluctuation occurs from -1.7 to 1.7 knots. That is, an annual fluctuation can contribute a speed of \pm 1.7 knots. Further low-frequency (longer than 512 days) variation is evident in signal a. This signal can also be considered as the signal of yearly (exactly 256 days) average wind speed. The duration for the average is long enough. The signal, however, contains approximately two-year undulations with small amplitudes. If the two-year undulation is ignored, the mean speed indicated by the dashed line is initially about 7 knots, slowing down to 4.7 knots at $D=1700$ (1995), followed by augmentation to 6.5 at $D=2800$ (1998). This variation constitutes a period of about 8.5 years as evidenced by the dashed line. This information is very useful for a long-term wind prediction and power production. The observation also explains why a long-term wind speed trend at a location should be known to run a wind farm productively. Signals $\mathrm{d}_{7}$ and $\mathrm{d}_{6}$ display oscillation with a period of about a half and a quarter year, respectively. The oscillation is, however, small ( \pm 2 knots). The $d_{5}$ and $d_{4}$ signals have some large amplitude variations in the ranges of peaks in $d_{8}$ signal. The amplitude is greater in $d_{4}\left( \pm 2.0\right.$ knots) than $d_{5}$ ( \pm 1.5 knots). The observation insinuates that the monthly variation in wind speed is stronger than the bimonthly variation and it occurs in the peak season (June to August) of wind speed. The $d_{3}$ and $\mathrm{d}_{2}$ signals display a spike at $D=1200$; the spike is nevertheless larger at $\mathrm{d}_{2}$ than $\mathrm{d}_{3}$. It has been mentioned that in signal $\mathrm{S}$ there is a spike at $D=1200$ where the magnitude of speed is about 27 knots, which can now be explained with a view on $\mathrm{d}_{2}$ signal that around $D=1200$ (1993) there was a persistent wind gust or storm in a period of 4 to 8 days. Similarly, another wind gust is observed in $\mathrm{d}_{1}$ signal at $D=2200$ (1996) for a shorter period of 2 to 4 days. Overall, wind speed variation is stronger for a period of one year $\left(\mathrm{d}_{8}\right)$, half a year $\left(\mathrm{d}_{7}\right)$, one month $\left(\mathrm{d}_{4}\right)$ and less than 8 days $\left(\mathrm{d}_{1}\right.$ and $\left.\mathrm{d}_{2}\right)$ but weaker for a period of a quarter year $\left(\mathrm{d}_{6}\right)$, bimonthly $\left(\mathrm{d}_{5}\right)$, and biweekly $\left(\mathrm{d}_{3}\right)$.

At Dhahran, a station on the east coast of Saudi Arabia, the raw signal ' $S$ ' in Figure 4 displays sharp spikes at $D=500,800,2000,3400,4150,4750,5400$. Gusty winds were afoot 
more frequently. Here the long-term variation shown by the dashed line in a represents a period of about 9 years. This long-term variation period is almost the same for both Abha and Dhahran. The speed fluctuates from 8.3 to 9.5 knots (dashed line), while that for Abha oscillates from 4.7 to 6.5 knots. Therefore, the mean speed over the whole duration can be considered as 8.9 knots for Dhahran and 5.6 knots for Abha. The contribution of the long-term variation to the speed is about \pm 0.6 and \pm 0.9 knots for Dhahran and Abha, respectively. The annual variation of speed $\left(\mathrm{d}_{8}\right.$ signal) is more regular for Dhahran than for Abha, forming a peak in the months of April to June of each year. This regularity was also reflected in the power spectrum results with a peak at $f=$ 0.0027 appearing sharper at Dhahran than at Abha. While the mean variation in amplitudes at Dhahran ( $\mathrm{d}_{8}$ signal) is about \pm 1.3 knots, that at Abha is about \pm 1.7 knots, i.e. slightly larger in the latter. The $d_{7}-d_{3}$ signals display almost the same characteristics as those for Abha. The $d_{2}$ and $d_{1}$ signals, however, have larger amplitudes at Dhahran than at Abha. The larger amplitudes at Dhahran result from the fact that Dhahran is $17 \mathrm{~m}$ above the sea level and very close $(3 \mathrm{~km})$ to the sea.

At Gizan (Figure 5), which is located on the south-west coast of Saudi Arabia, the long-term variation period (dashed line) is slightly longer, about 12 years with a change in speed from 5.0 to 7.5 knots. The entire duration average is about 6.25 knots. The annual variation in amplitude is very small here, about \pm 0.7 knots ( $\mathrm{d}_{8}$ signal). Because of the small amplitude, the corresponding peak at $f=0.0027$ in the FFT power spectrum was not distinguished enough (Figure 2c). Table 3 extracts important intrinsic features of wind speed analysis results in Figures 3-11. The long-term (16 years) mean speed (second column), long-term period (third column) and long-term fluctuation (fourth column) are extracted from as signals. On the other hand, annual fluctuation (fifth column), monthly fluctuation (sixth column) and half-weekly fluctuation in speed are obtained from $\mathrm{d}_{8}, \mathrm{~d}_{4}$ and $\mathrm{d}_{1}$ signals, respectively. Having smaller fluctuations, other data are not included in Table 3. The data in Table 3 are plotted in Figs. 12 and 13 for the sake of a better perceptibility of comparison between different locations. The long-term mean speed is a minimum of 5.6 knots at Abha (Table 3, Figure 12). Dhahran, Guriat and Turaif undergo a higher speed of 8.9, 8.1 and 8.6 knots, respectively (Table 3, Figure 13). It is interesting that the wind speed has a long period of about 10 (8.5 to 1.2) years (third column of Table 3 ) which contributes to a change in speed by \pm 0.6 to \pm 1.6 knots (fourth column) depending on the location. 
Table 3

Intrinsic features of wind speed at different locations. June to August is the wind peak season.

\begin{tabular}{|c|c|c|c|c|c|c|}
\hline \multirow[b]{2}{*}{ Site } & \multicolumn{3}{|c|}{$\mathrm{a}_{8}$} & \multirow{2}{*}{$\begin{array}{c}\mathrm{d}_{8} \\
\text { Annual } \\
\text { fluctuation } \\
\text { (knots) }\end{array}$} & \multirow{2}{*}{$\begin{array}{c}\mathrm{d}_{4} \\
\text { Monthly } \\
\text { fluctuation } \\
\text { June-August } \\
\text { (knots) }\end{array}$} & \multirow{2}{*}{$\begin{array}{c}\mathrm{d}_{1} \\
\text { Half-weekly } \\
\text { fluctuation } \\
\text { (knots) }\end{array}$} \\
\hline & $\begin{array}{c}\text { Long-term } \\
\text { mean } \\
\text { speed } \\
\text { (knots) }\end{array}$ & $\begin{array}{l}\text { Long-term } \\
\text { period } \\
\text { (years) }\end{array}$ & $\begin{array}{l}\text { Long-term } \\
\text { fluctuation } \\
\text { (knots) }\end{array}$ & & & \\
\hline Abha & 5.6 & 8.5 & \pm 0.9 & \pm 1.7 & \pm 2.6 & \pm 2.5 \\
\hline Dhahran & 8.9 & 9 & \pm 0.6 & \pm 1.3 & \pm 2.9 & \pm 3.3 \\
\hline Gizan & 6.25 & 12 & \pm 0.9 & \pm 0.7 & \pm 1.5 & \pm 1.6 \\
\hline Guriat & 8.1 & 9 & \pm 0.9 & \pm 3.0 & \pm 3.0 & \pm 3.8 \\
\hline Hail & 6.0 & 9 & \pm 1.5 & \pm 1.0 & \pm 2.4 & \pm 3.0 \\
\hline Jeddah & 7.1 & 10.5 & \pm 0.9 & \pm 1.1 & \pm 2.4 & \pm 2.5 \\
\hline Riyadh & 6.0 & 9.5 & \pm 0.65 & \pm 1.1 & \pm 2.8 & \pm 2.9 \\
\hline Turaif & 8.6 & 10 & \pm 1.4 & \pm 0.9 & \pm 2.5 & \pm 3.5 \\
\hline Yanbu & 7.3 & 10.5 & \pm 1.6 & \pm 1.7 & \pm 2.5 & \pm 3.0 \\
\hline
\end{tabular}

The long-term contribution is, however, maximum at Yanbu ( \pm 1.6 knots $)$ and Hail $( \pm 1.5$ knots). It was found in the FFT analysis results that Abha, Dhahran, Guriat and Yanbu showing a sharp peak at $f=0.0027$ preserved a more regular annual repetition than Gizan, Hail, Jeddah, Riyad and Turaif. The data in the fifth column agree with the observation in the FFT analysis results, displaying larger fluctuations ( \pm 1.3 to \pm 3.0 knots $)$ at the former locations and smaller ( \pm 0.7 to \pm 1.1 knots) at the latter locations. The annual variation is, however, the largest $( \pm 3.0$ knots) at Guriat and the smallest ( \pm 0.7 knots) at Gizan. Except for the small value (1.5 knots) at Gizan, the monthly fluctuation is less dependent on location, nestling between \pm 2.4 and \pm 3.0 knots. Among the long-term, annual, monthly and half-weekly fluctuations (Table 3 and Figure 12 ), and the half-weekly fluctuation is the largest at all locations, varying from \pm 1.6 to \pm 3.8 knots. This observation points to the fact that the daily fluctuation should also to be investigated. Overall, the annual, monthly, and half-weekly fluctuations are the largest at Guriat and the smallest at Gizan. The most possible cause behind the largest and smallest fluctuations at Guriat and Gizan, respectively, is that while Guriat is a high land with low and high hills, Gizan is a coastal area only $5 \mathrm{~m}$ above the sea level. The information in Table 3 will be very useful for short- and long-term wind forecasts, hence to distinguish idle and running periods of a wind turbine. Using wavelet transform, Chellali et al. (2010) made a time-period analysis of wind 
speed data recorded at Adrar, Algeria for four years (2005 to 2009). Their analyzing period ranged from 2 to 64 days only, which is rather small compared with our range of 2 to 512 days investigated. They observed the dominant oscillation of periods between 2 and 16 days including intra-seasonal oscillations of periods between 30 and 60 days.

\section{Conclusions}

FFT and wavelet analyses were done of daily average wind speed time series data at nine different locations, namely Abha, Dhahran, Gizan, Guriat, Hail, Jeddah, Riyadh, Turaif and Yanbu in Saudi Arabia over the period 1990 to 2005. The analyses extracted the intrinsic features of wind speed, including long-term, annual, half-yearly, quarter-yearly, monthly, biweekly, weekly and half-weekly fluctuations. The information on speed fluctuations at different periods is very useful for meteorological purposes including wind and weather forecasting.

The wind speed over Saudi Arabia has a long period of about 10 years contributing to change in speed by \pm 0.6 to \pm 1.6 knots depending on the locations. The long-term contribution is maximum ( \pm 1.6 knots) at Yanbu and minimum ( \pm 0.6 knots) at Dhahran. The long-term mean wind speed is 5.6, 8.9, 6.25, 8.1, 6.0, 7.1, 6.0, 8.6 and 7.3 knots at Abha, Dhahran, Gizan, Guriat,

Hail, Jeddah, Riyadh, Turaif and Yanbu, respectively. The annual fluctuation in wind speed is larger ( \pm 1.3 to \pm 3.0 knots) and more regular at Abha, Dhahran, Guriat and Yanbu, while smaller ( \pm 0.7 to \pm 1.1 knots) and less regular at Gizan, Hail, Jeddah, Riyad and Turaif, with the greatest $( \pm 3.0)$ and smallest $( \pm 0.7)$ at Guriat and Gizan, respectively. Among long-term, annual, halfyearly, quarter-yearly, monthly, biweekly, weekly and half-weekly fluctuations, the largest change in wind speed occurs half-weekly, by about \pm 1.6 to \pm 3.8 knots depending on location. The highland and coastal sites, Dhahran, Guriat and Yanbu, correspond to larger annual, monthly and half-weekly fluctuations of wind speed.

\section{Acknowledgement}

The author wishes to acknowledge the support of the Research Institute of King Fahd University of Petroleum and Minerals, Dhahran, Saudi Arabia.

\section{References}


Abdel-Aal, R.E., Al-Garni, A.Z., 1997. Forecasting monthly electric energy consumption in eastern Saudi Arabia using univariate time-series analysis. Energy 22, 1059-1069.

Aksoy, H., Toprak, Z.F., Aytek, A., 2004. Unal NE. Stochastic generation of hourly mean wind speed data. Renewable Energy 29, 2111-2131.

Alam, M.M., Moriya, M., Sakamoto, H., 2003. Aerodynamic characteristics of two side-by-side circular cylinders and application of wavelet analysis on the switching phenomenon. Journal of Fluids and Structures 18, 325-346.

Alam, M.M., Sakamoto, H., 2005. Investigation of Strouhal frequencies of two staggered bluff bodies and detection of multistable flow by wavelets. Journal of Fluids and Structures 20, 425-449.

Catalão, J.P.S., Pousinho, H.M.I., Mendes, V.M.F., 2011. Short-term wind power forecasting in Portugal by neural networks and wavelet Transform. Renewable Energy 36, 1245-1251.

Chavez, S.G., Bernat, J.X., Coalla, H.L., 1999. Forecasting of energy production and consumption in Asturias (northern Spain). Energy 24, 183-198.

Chellali, F., Khellaf, A., Belouchrani, A., 2010. Wavelet spectral analysis of the temperature and wind speed data at Adrar, Algeria. Renewable Energy 35, 1214-1219.

Chellali, F., Khellaf, A., Belouchrani, A., Recioui, A., 2011. A contribution in the actualization of wind map of Algeria. Renewable and Sustainable Energy Reviews 15, 993-1002.

Costa, A., Crespo, A., Navarro, J., Lizcano, G., Madsen, H., Feitosa, E., 2008. A review on the young history of the wind power short-term prediction. Renewable and Sustainable Energy Reviews 12, 1725-1744.

Dubrulle, B., 1994. Intermittency in fully developed turbulence: log-Poisson statistics and generalized scale covariance. Physical Review Letters 73, 959-962.

Ekonomou, L., 2010. Greek long-term energy consumption prediction using artificial neural networks. Energy 35(2), 512-517.

Farge, M., 1992. Wavelet transforms and their applications to turbulence. Annual Review of Fluid Mechanics 24, 395-457.

Garcia-Marin, A.P., Estevez, J., Jimenzez-Hornero, F.J., Ayuso-Munioz, J.L. 2013. Multifractal analysis of validated wind speed time series. Chaos, Non-Linear Science 23, 013133. 
Giorgi, M.D., Ficarella, A., Tarantino, M., 2011. Assessment of the benefits of numerical weather predictions in wind power forecasting based on statistical methods. Energy 36, 3968-3978.

Gurley, K.R., Tognarelli, M.A., Kareem, A., 1997. Analysis and simulation tools for wind engineering. Probabilistic Engineering Mechanics 12, 9-31.

Hang, T., Nguyen, I., Nabney, T., 2010. Short-term electricity demand and gas price forecasts using wavelet transforms and adaptive models, Energy 35, 3674-3685.

Jaramillo, O.A., Borja M.A., 2004. Winds peed analysis in La Ventosa, Mexico: a bimodal probability distribution case. Renewable Energy 29, 1613-1630.

Jiang, Y., Tang, B., Qin, Y., Liu, W., 2011. Feature extraction method of wind turbine based on adaptive Morlet wavelet and SVD. Renewable Energy 36, 2146-2153.

Kareem, A., Kijewski, T., 2002. Time-frequency analysis of wind effects on structures. Journal of Wind Engineering and Industrial Aerodynamics 90, 1435-1452.

Karegar, H.K., Sobhani, B., 2012. Wavelet transform method for islanding detection of wind turbines. Renewable Energy 38, 94-106.

Kelley, N.D., Osgood, R.M., Bialasiewicz, J.T., Jakubowski, A., 2000. Using wavelet analysis to assess turbulence/rotor interactions. Wind Energy 3, 121-134.

Kitagawa, T., Nomura, T., 2003. A wavelet-based method to generate artificial wind fluctuation data. Journal of Wind Engineering and Industrial Aerodynamics 91, 943-964.

Lee, B.B., Wu, L.C., Kao, C.C., 2007. Seasonal variations of wind and wave over Taiwan waters. Marine Geophysical Researches 28, 183-90.

Liu, W.Y., Tang, B.P., Jiang, Y.H., 2010. Status and problems of wind turbine structural health monitoring techniques in China. Renewable Energy 35(7), 1414-1418.

Mellit, A., Benghanem, M., Kalogirou, S. A., 2006. An adaptive wavelet-network model for forecasting daily total solar-radiation. Applied Energy 83, 705-722.

Pettit, C.L., Jones, N.P., 2002. Ghanem R. Detection and simulation of roof-corner pressure transients. Journal of Wind Engineering and Industrial Aerodynamics 90, 171-200.

Politis, E.S., Prospathopoulos, J., Cabezon, D., Hansen, K.S., 2012. Chaviaropoulos PK, Barthelmie RJ. Modeling wake effects in large wind farms in complex terrain: the problem, the methods and the issues. Wind Energy 15, 161-182. 
Rossi, R., Lazzari, M., Vitaliani, R., 2004. Wind field simulation for structural engineering purposes. International Journal Numerical Methods in Engineering 61, 738-63.

She, Z., Waymire, E.C., 1995. Quantized energy cascade and log-Poisson statistics in fully developed turbulence. Physical Review Letters 74, 262-265.

Shinozuka, M., Deodatis, G., 1991. Simulation of stochastic processes by spectral representation. Applied Mechanical Review 44, 191-204.

Tang, B., Liu, W., Song, T., 2010. Wind turbine fault diagnosis based on Morlet wavelet transformation and Wigner-Ville distribution. Renewable Energy 35, 2862-2866.

Torrence, C., Compo, G.P., 1998. A practical guide to wavelet analysis. Bulletin of the American Meteorological Society 79(1), 61-78.

Turbelin, G., Ngae, P., Grignon, M., 2009. Wavelet cross-correlation analysis of wind speed series generated by ANN based models. Renewable Energy 34, 1024-1032.

Velasco, V.M., Mendoza, B., 2008. Assessing the relationship between solar activity and some large scale climatic phenomena. Advances in Space Research 42, 866-78.

Weng, H., Lau, K.M., 1994. Wavelets, period doubling, and time-frequency localization with application to organization of convection over the tropical western Pacific. Journal of the Atmospheric Sciences 51, 2523-41.

Xueli, A., Dongxiang, J., Shaohua, L., Minghao, Z., 2011. Application of the ensemble empirical mode decomposition and Hilbert transform to pedestal looseness study of direct-drive wind turbine. Energy 36, 5508-5520.

Yamada, M., Ohkitani, K., 1991. Orthonormal wavelet analysis of turbulence. Fluid Dynamics Research 8, 101-115.

Yong, R.K., 1998. Wavelet theory and its application. 6th edition. USA: Kluwer Academic Publishers.

Zeldin, B., Spanos, P., 1995. Random field simulation using wavelet bases, applications of statistics and probability. Proceeding of the ICASP 7 Conference, Paris, France, 1995, 2: $1275-1283$. 


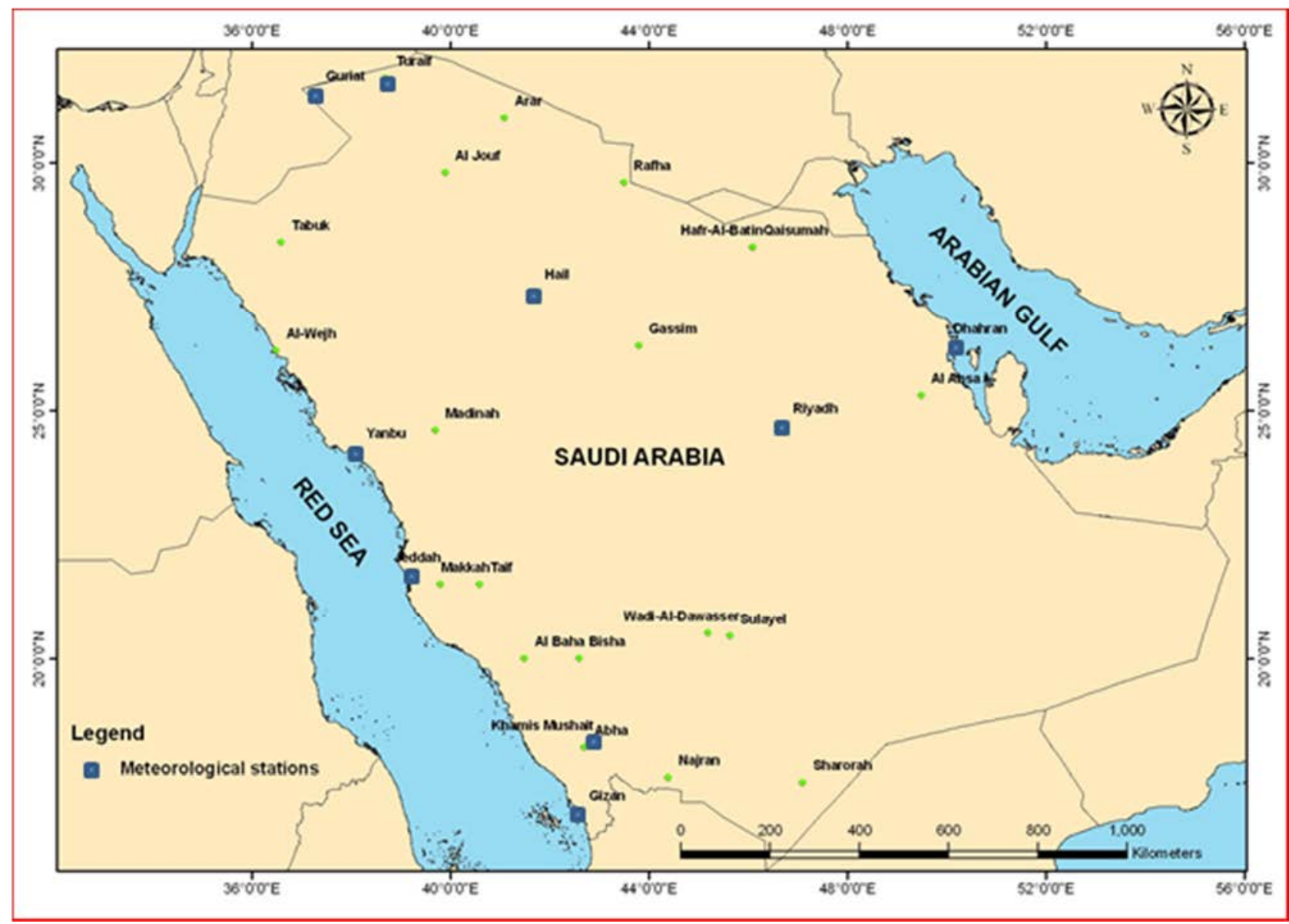

Fig. 1. Physical locations of the meterological stations used in the study. 

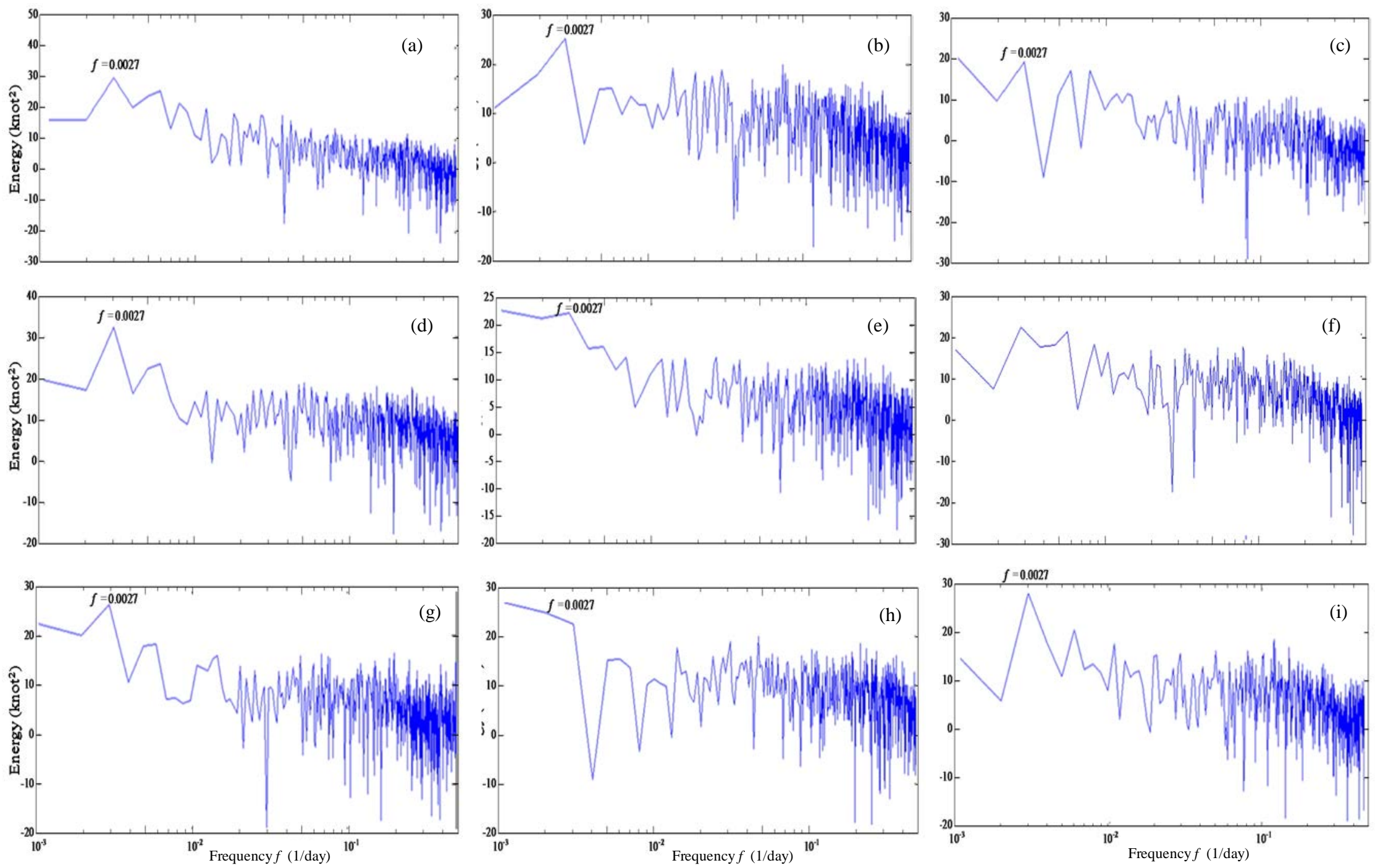

Fig. 2. FFT power spectrum of wind speed data for (a) Abha, (b) Dhahran, (c) Gizan, (d) Guriat, (e) Hail, (f) Jeddah, (g) Riyadh, (h) Turaif, and (i) Yanbu. 


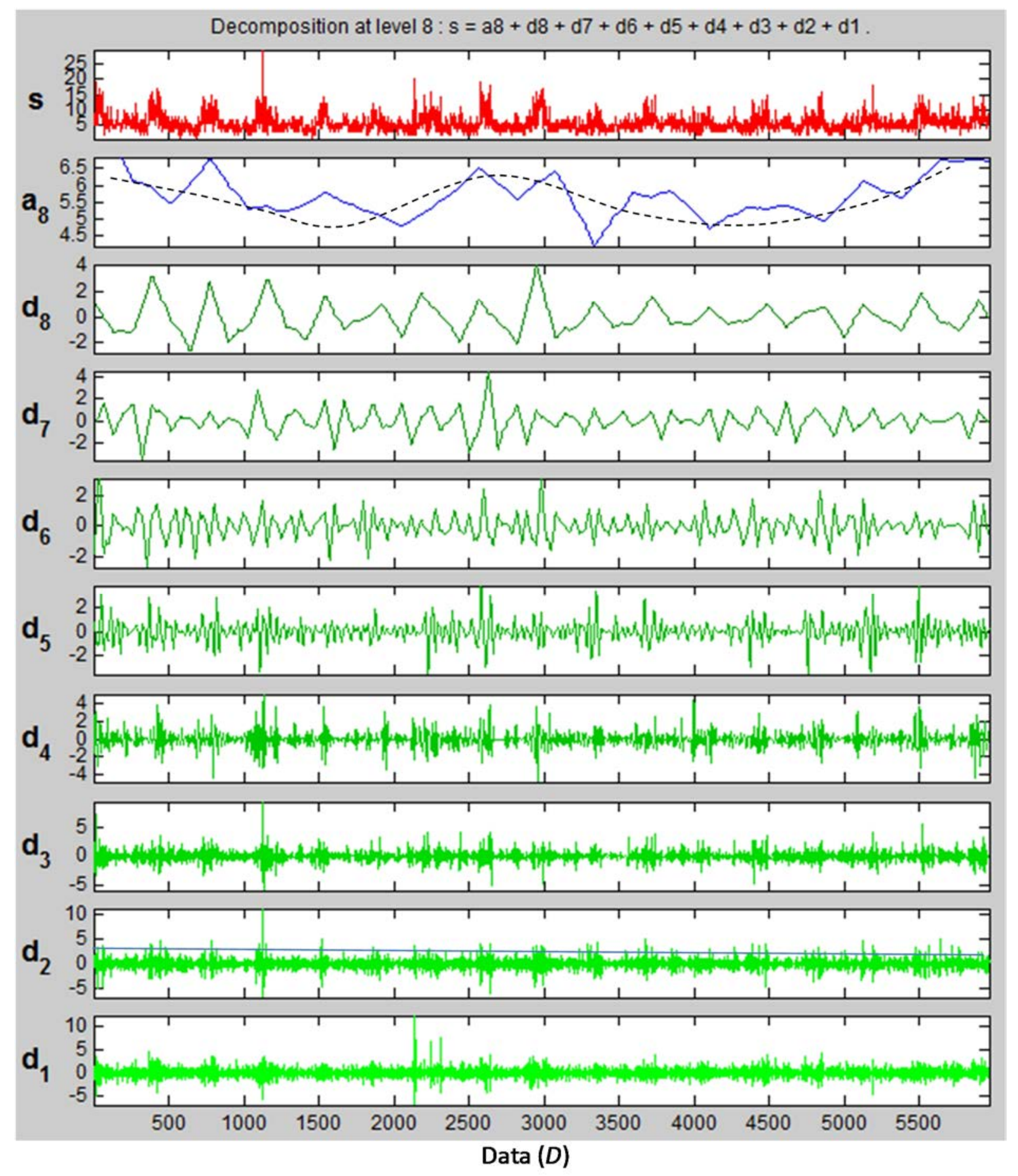

Fig. 3. Decomposition of wind speed time series data for Abha using DB8. 


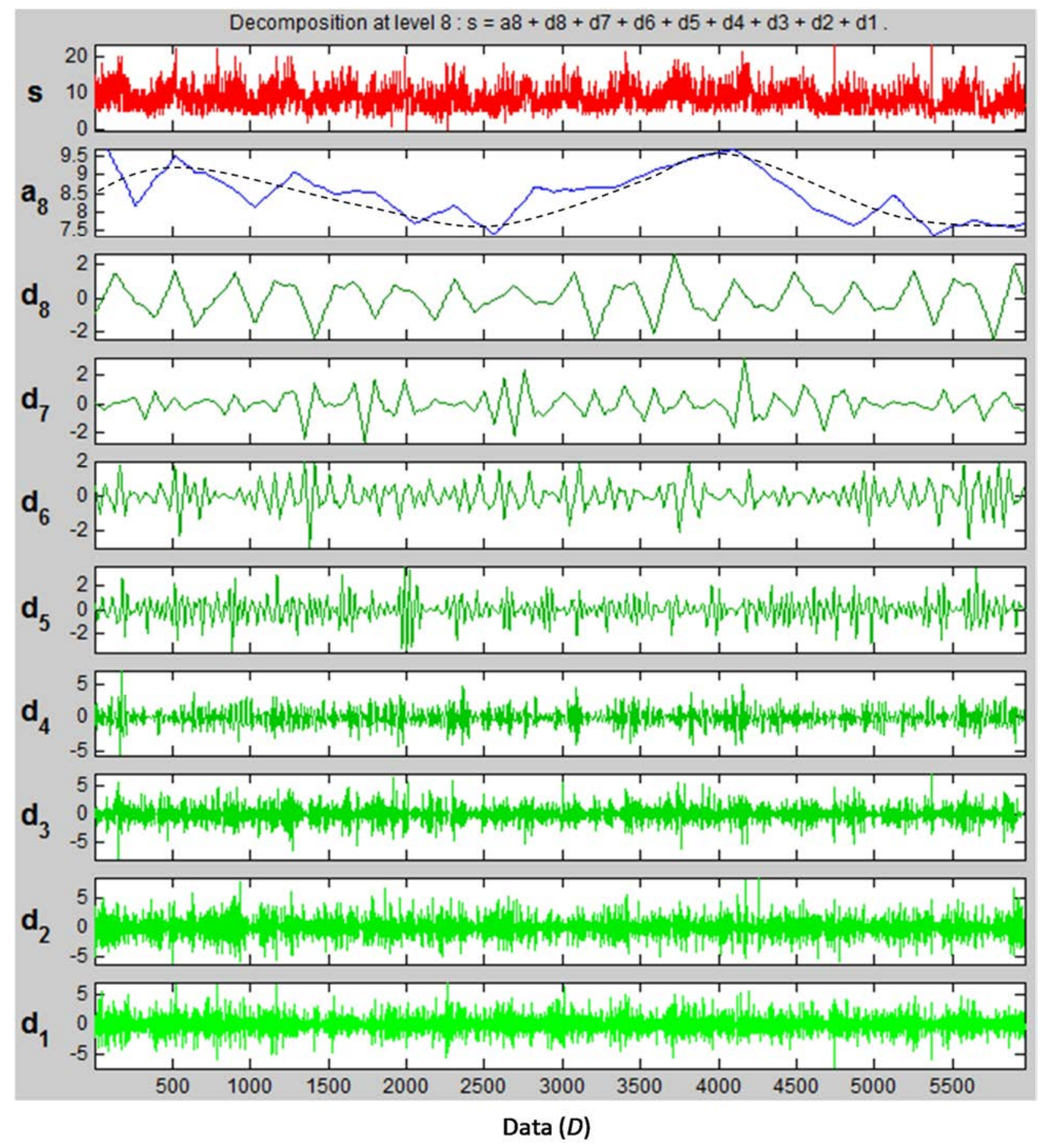

Fig. 4. Decomposition of wind speed time series data for Dhahran using DB8. 


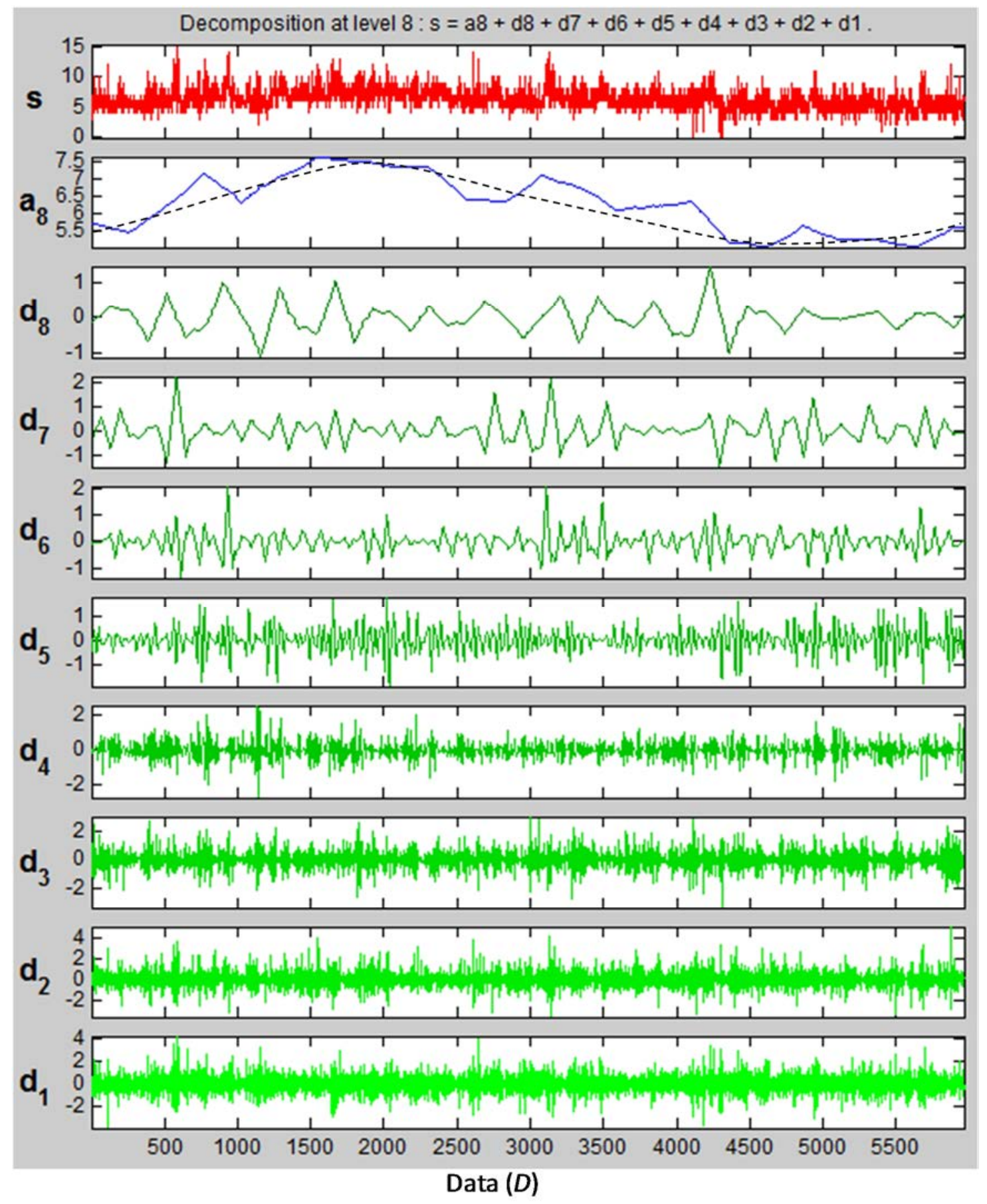

Fig. 5. Decomposition of wind speed time series data for Gizan using DB8. 


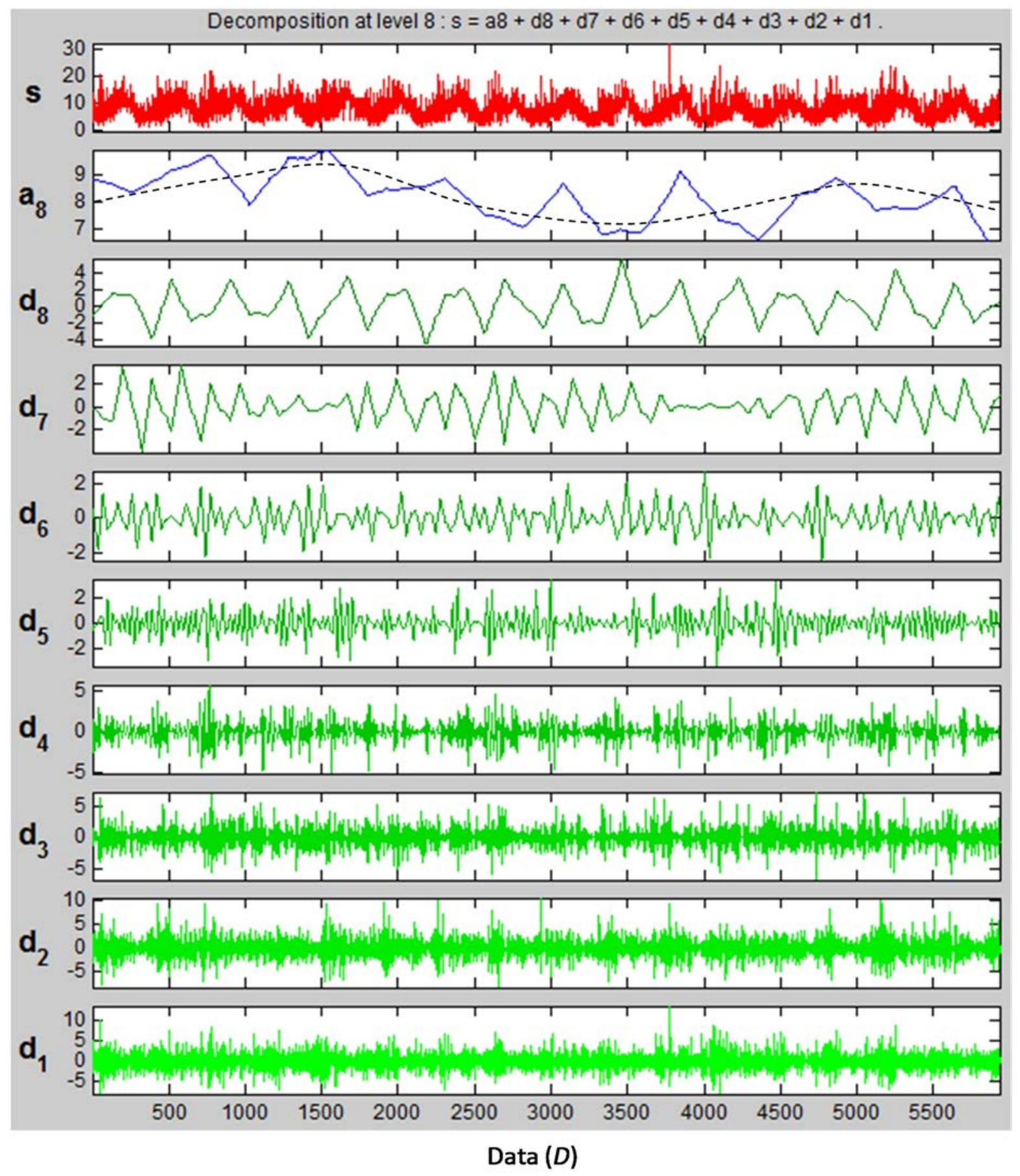

Fig. 6. Decomposition of wind speed time series data for Guriat using DB8. 


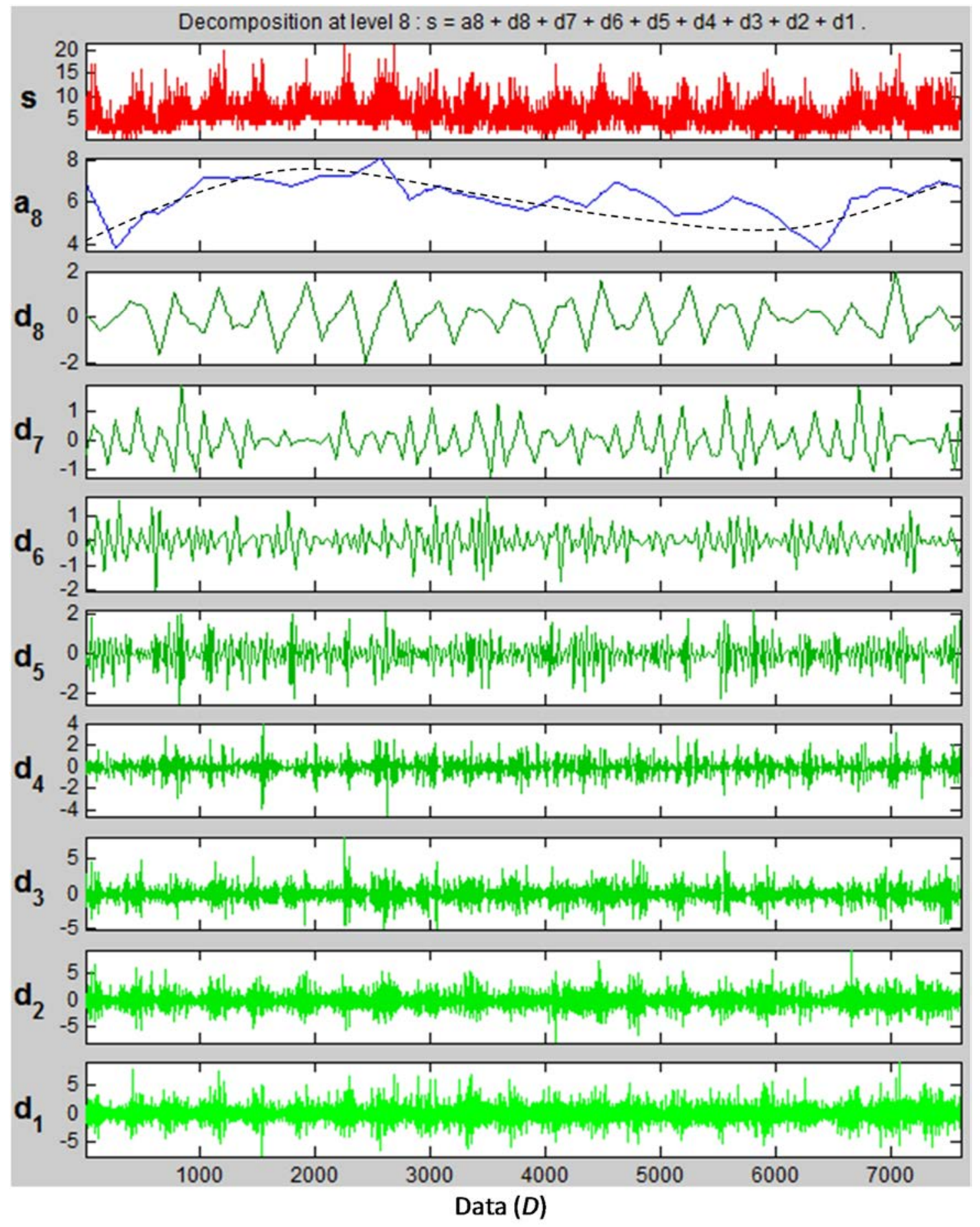

Fig. 7. Decomposition of wind speed time series data for Hail using DB8. 


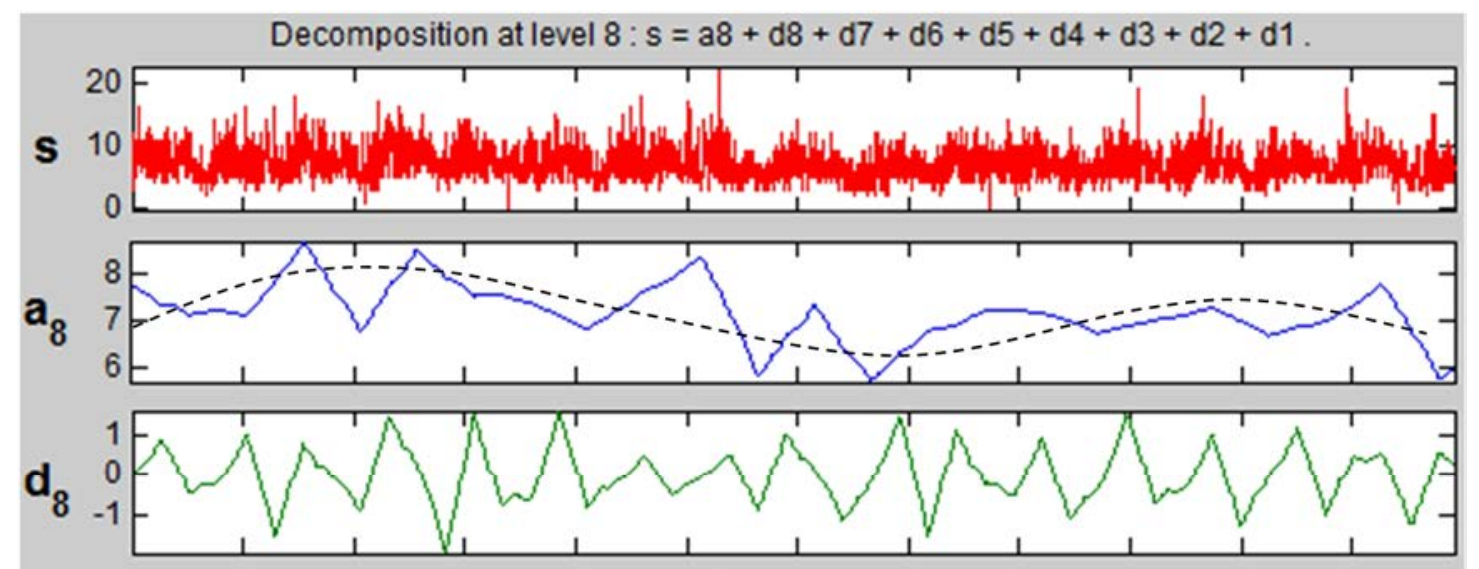

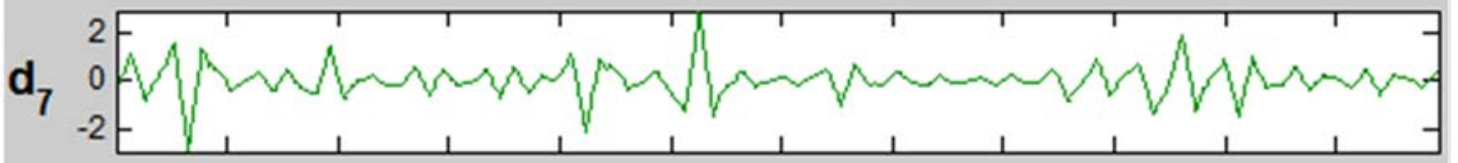

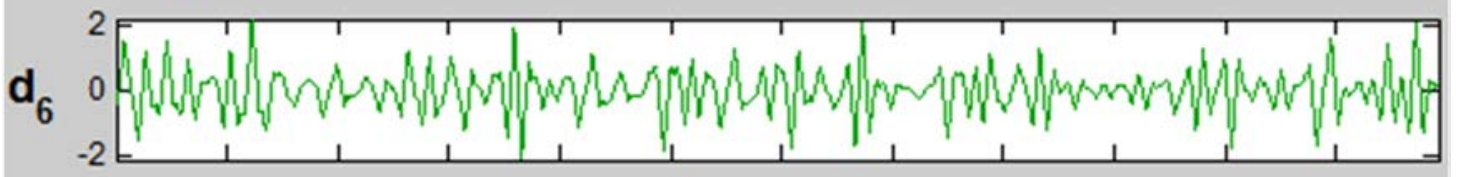

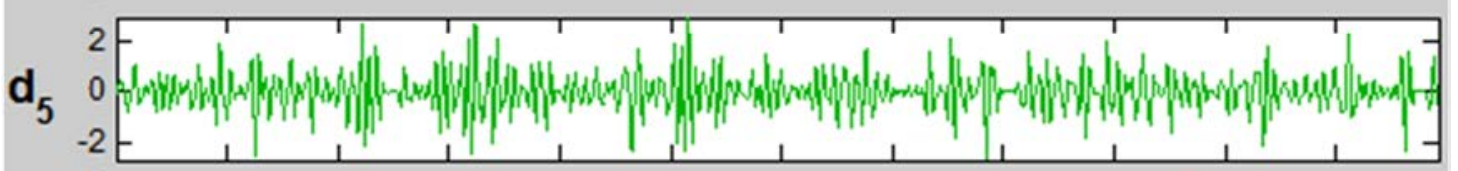

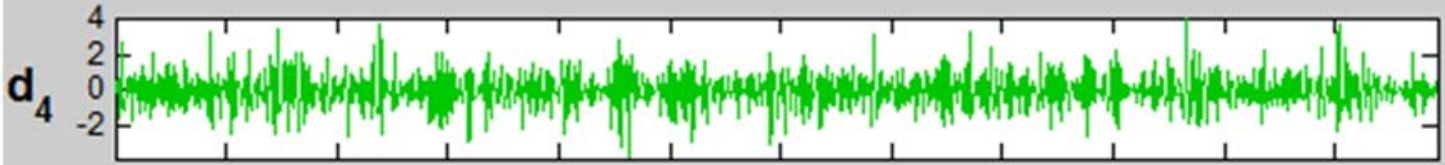

$0_{3}^{2} 0_{0}^{5}$

$\mathbf{d}_{2}{ }_{-5}^{5}$

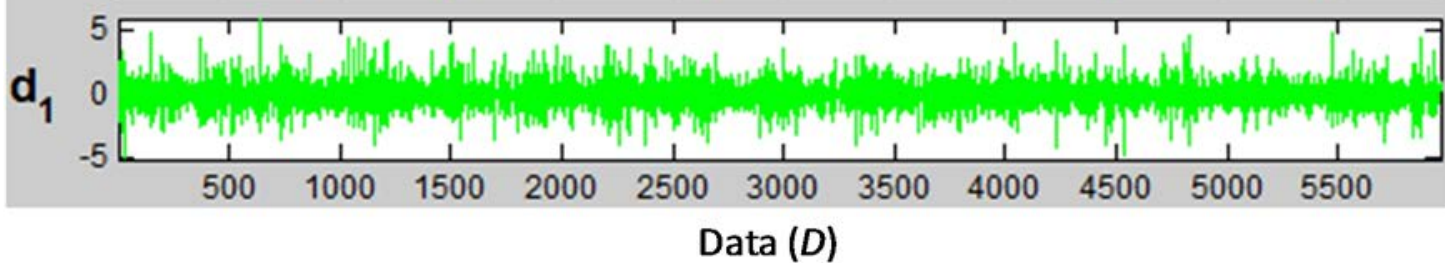

Fig. 8. Decomposition of wind speed time series data for Jeddah using DB8. 


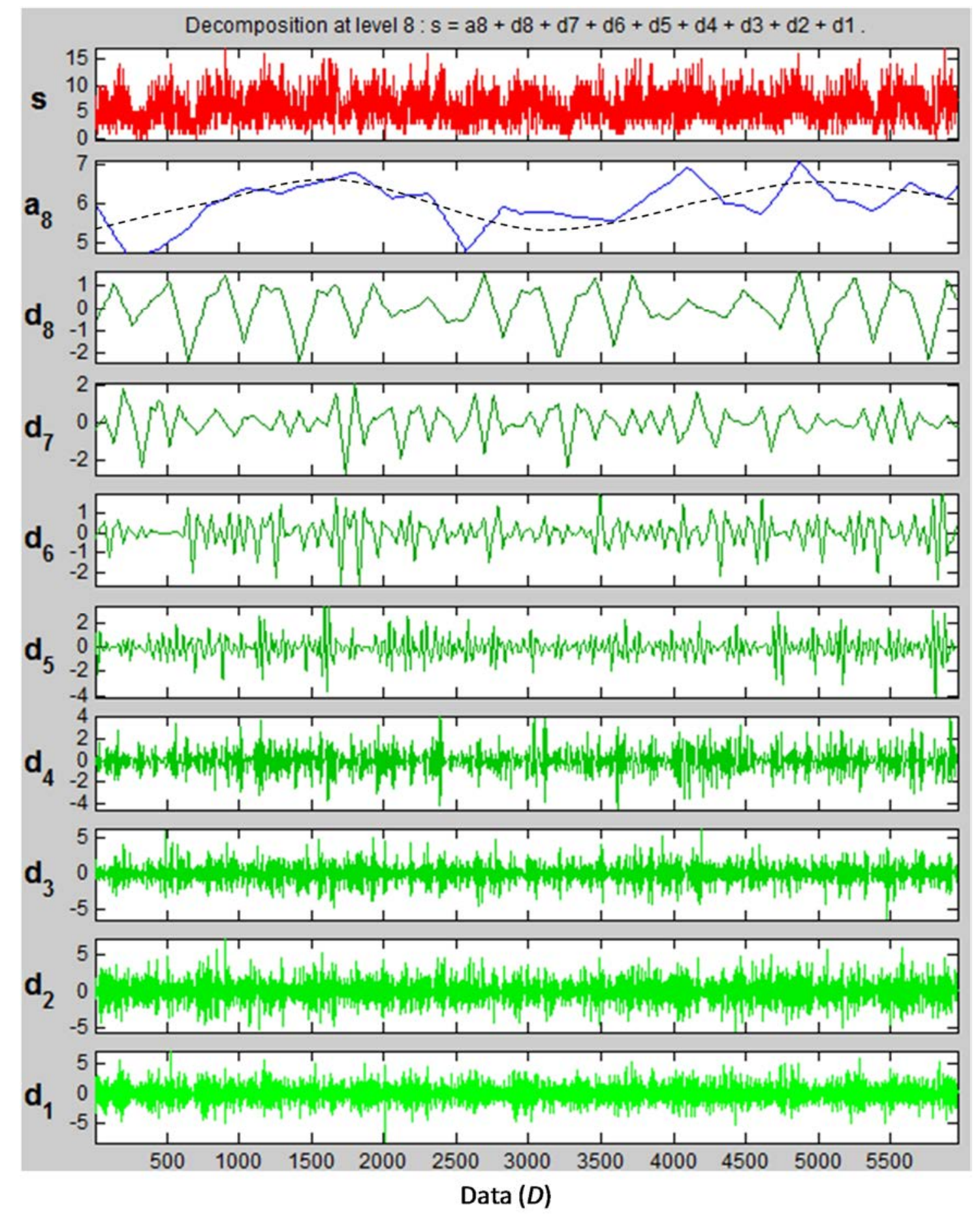

Fig. 9. Decomposition of wind speed time series data for Riyadh using DB8. 


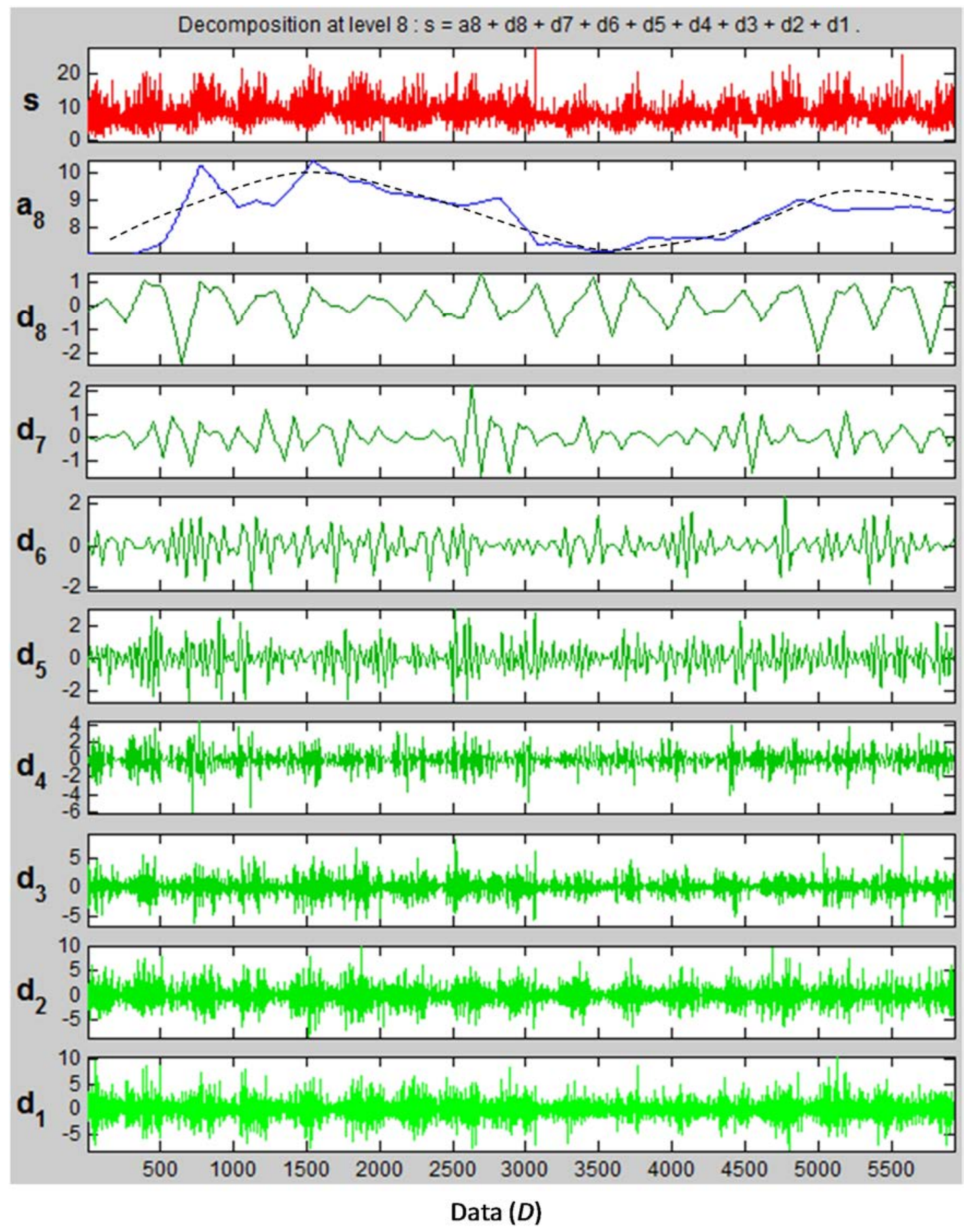

Fig. 10. Decomposition of wind speed time series data for Turaif using DB8. 


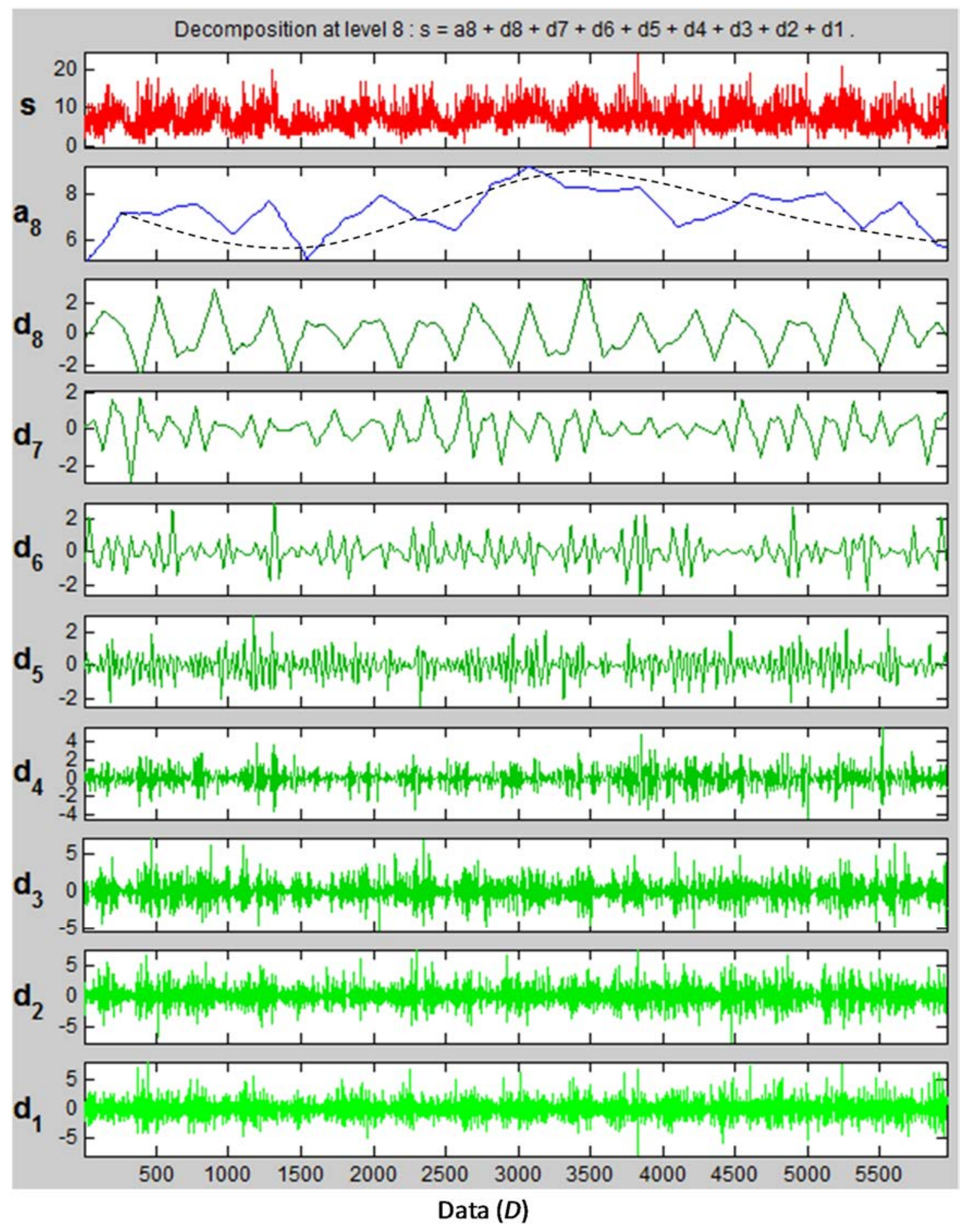

Fig. 11. Decomposition of wind speed time series data for Yanbu using DB8. 


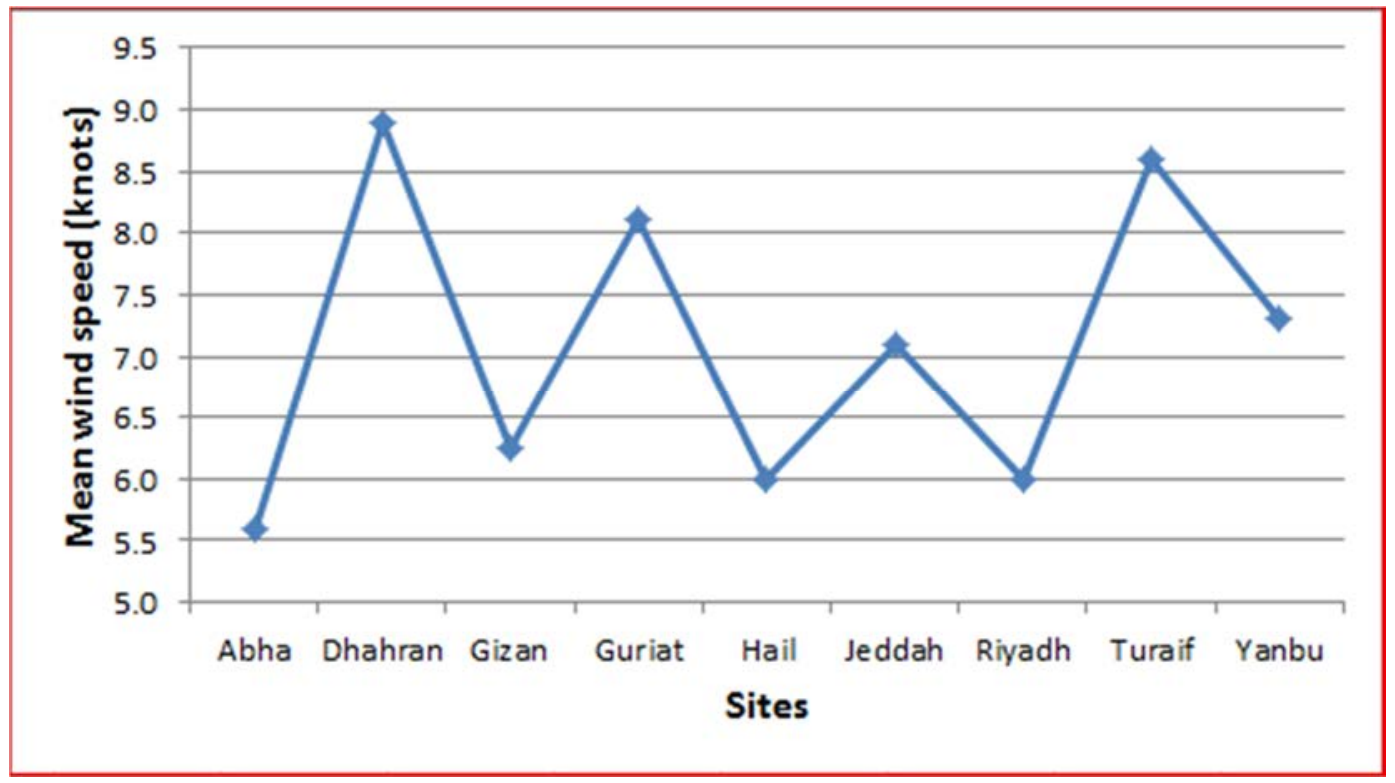

Fig. 12. Long-term (16 years) mean wind speed at different sites.

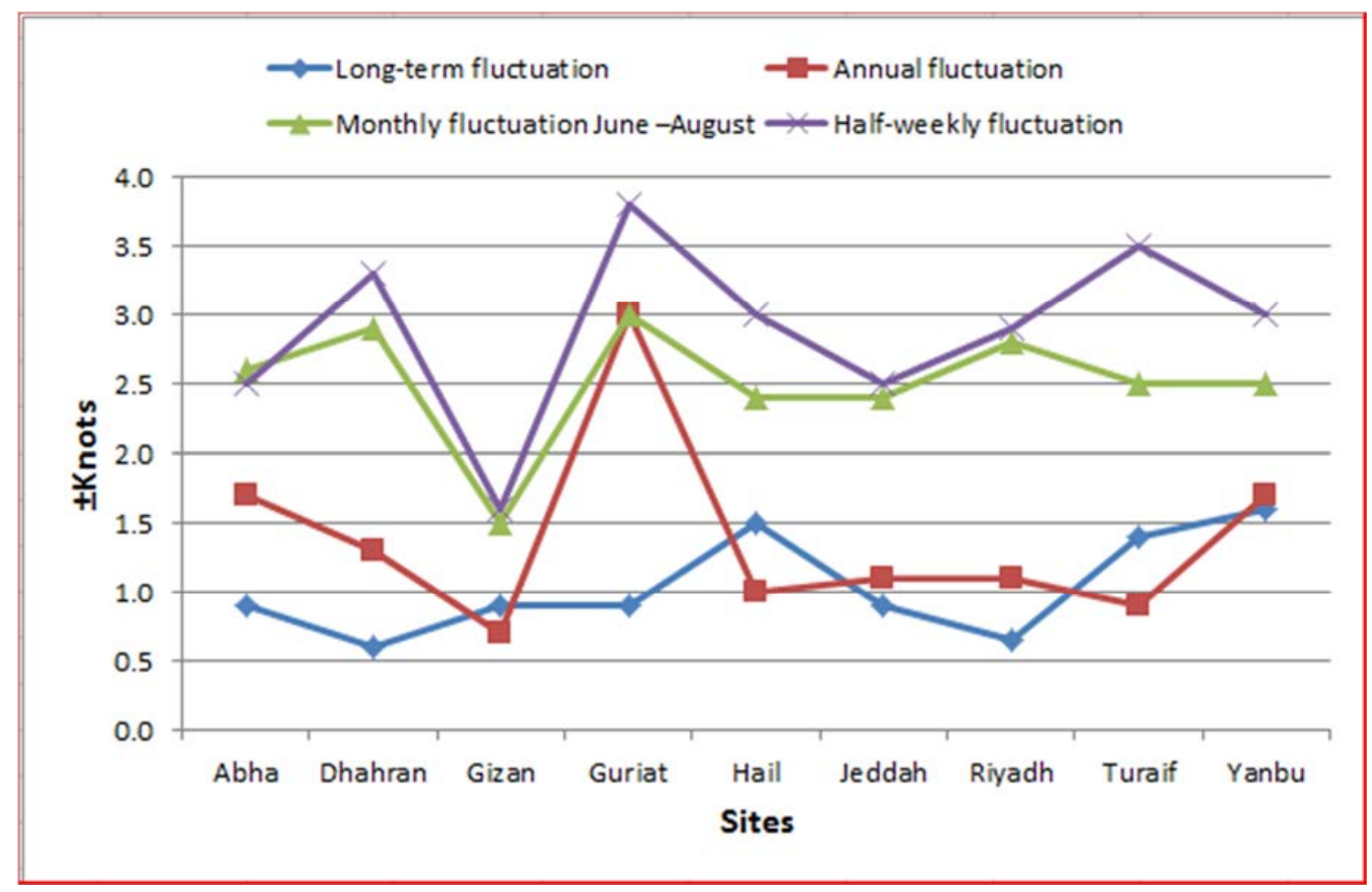

Fig. 13. Contributions of fluctuation in wind speed at different periods. 